\title{
Parametric Design in Building Reconfiguration: An Application Towards Environmental Quality
}

\author{
João Pedro Deodato Barretoํㅜ ${ }^{1}$ José Fabricio Sousa Silveira' ${ }^{1}$, Raquel \\ Magalhães Leite ${ }^{1}$ \\ ${ }^{1}$ Federal University of Ceará, Brazil \\ pedrodeodato@arquitetura.ufc.br \\ fabricio.sousa@arquitetura.ufc.br \\ raquelleite@daud.ufc.br
}

\begin{abstract}
This paper introduces an application study that analyzes environmental variables in existing buildings, focusing on the area of thermal and luminous quality. The object of study is an academic office building, where adaptability emerges as a pivotal feature to provide environmental quality to the occupants. The analysis methodology was based on the use of parametric simulations that allow to explore different scenarios and solutions, in addition, an on-site measurement was carried out for a better understanding of the object of study. In this research, the potential of parametric technologies is analyzed as an auxiliary tool in design decisions, which seeks to explore possibilities, rearranging variables to reach better environmental solutions.
\end{abstract}

Keywords: Parametric simulations, Sustainability, Environmental quality, Adaptability, Building reconfiguration

\section{Introdução}

A análise do condicionamento ambiental é elementar no exercício projetual arquitetônico, uma vez que a materialidade construída está incorporada a um contexto não apenas sociocultural, mas bioclimático. Os fenômenos climáticos interagem objetivamente com o edifício, intervindo na condição de conforto dos usuários, e, consequentemente, é necessário ter cautela e ponderação ao correlacionar o projeto de arquitetura aos domínios climáticos. Na conjuntura contemporânea, a tecnologia está em infrene desenvolvimento no âmbito da arquitetura, e como decorrência várias ferramentas se integram ao processo de projeto. Em observância a esse cenário, que oportuniza a implementação desses instrumentos, a parametria é uma alternativa que agiliza processos de 
análise e criação digital, resguardando a unicidade das variáveis, elencando um conjunto de resultados distintos, que se adequam a critérios particularizados, conexos ao projeto de arquitetura.

Esse sistema gera resultados precisos e eficientes com rapidez, acrescendo as possibilidades de resoluções projetuais efetivas. Uma análise paramétrica dos fatores bioclimáticos possibilita uma rápida exploração dos fenômenos climáticos e de suas relações com os elementos arquitetônicos. 0 processo paramétrico ou associativo (Oxman, 2006) se diferencia dos demais projetos digitais pela sua capacidade de analisar variáveis (parâmetros) e organizar o projeto como um fluxo de dados inter-relacionados, possibilitando intervenções em pontos específicos. Isso torna possível, por exemplo, correlacionar as principais variáveis do conforto térmico, concedendo ao arquiteto um panorama sobre as condições de conforto, e como se pode alterálas. Como variáveis mais relevantes para o conforto térmico, pode-se elencar:

Temperatura, umidade e velocidade do ar e radiação solar incidente. Guardam estreitas relações com regime de chuvas, vegetação, permeabilidade do solo, águas superficiais e subterrâneas, topografia, entre outras características locais que podem ser alteradas pela presença humana. (Frota \& Schiffer, 2001, p. 15)

O projeto paramétrico pode ser utilizado para criar, intervir ou alterar a materialidade construída, buscando resguardar as condições de conforto térmico de um objeto arquitetônico. Nessa circunstância, a parametria, associada a simulações computacionais, é proficiente não apenas no transcurso do exercício projetual, mas para análises que resultem em reconfigurações de edifícios pré-existentes.

Por exemplo, uma aplicação de simulações de desempenho com ferramentas digitais foi realizada por Tsuda e Duarte (2018) em um projeto de reabilitação, para uso residencial, do edifício onde funcionou o Hotel Columbia Palace, em São Paulo. O estudo também incorporou medições in loco, a fim de avaliar e propor intervenções de acordo com condições de desempenho luminoso, acústico e ergonômico. Apesar de prever um fluxo interativo de análise e síntese, não chegou a incorporar um processo paramétrico. Destacase, no trabalho, a articulação coerente entre questões do edifício, vinculadas à sua performance, e dos ocupantes, evidenciadas na criação de diferentes tipologias de apartamentos, inclusive com planta livre. Além disso, as autoras demonstram, através da criação de três cenários distintos, a condição mais favorável e econômica de alteração das aberturas para obtenção de um bom desempenho luminoso.

A consideração da variável temporal no ambiente construído é um ponto de partida para proporcionar maior adaptabilidade aos edifícios, alongando sua vida útil. Do ponto de vista climático, esse pressuposto alinha-se ao modelo de conforto adaptativo, o qual traz como premissa o diálogo entre o ser humano e o edifício, ou seja: maiores níveis de satisfação são obtidos quando o edifício é dotado de características que possibilitem aos ocupantes ajustar elementos para atingir conforto, segundo suas demandas pessoais e variações climáticas 
sazonais (Monteiro et al., 2015). Essas modificações podem ter a ver com componentes físicos, como a regulagem da angulação de uma janela veneziana, ou com a ocupação do espaço, como a mudança no layout para posicionar-se mais favoravelmente à incidência de luz.

Nos espaços de trabalho, onde as demandas e os ocupantes variam com frequência, a adaptabilidade é um princípio importante para atingir qualidade ambiental. Como discutido por Gonçalves (2019), os atributos principais dos ambientes de trabalho contemporâneos devem ser (1) permeabilidade entre espaço interno e externo com uso de estratégias bioclimáticas passivas, (2) capacidade de adaptação ambiental para atingir conforto e (3) flexibilidade espacial. A autora discute que, contrapondo-se aos edifícios herméticos da segunda metade do Século XX, os ambientes de trabalho atuais passam por uma revisão que resgata alguns princípios bioclimáticos da arquitetura modernista, mas agregam soluções mais precisas, vinculadas à inserção de análises computacionais no fluxo de projeto (Gonçalves, 2019). Com a pandemia de Covid 19, essas questões têm-se tornado ainda mais urgentes, acentuando-se, por exemplo, a importância da ventilação natural e da flexibilidade na organização interna dos ambientes, a fim de proporcionar maior qualidade ambiental.

Diante do exposto, o objetivo deste artigo é explorar potencialidades e desafios das simulações computacionais de variáveis ambientais em edifícios já existentes, dentro de um fluxo de projeto paramétrico, sob a ótica da adaptabilidade. Para tal, foi realizado um estudo de aplicação em um edifício existente incorporando também levantamentos de dados e visitas ao local.

\subsection{Objeto de Estudo}

O objeto de estudo é um bloco do Departamento de Arquitetura e Urbanismo da Universidade Federal do Ceará. Construído na década de 1970 para abrigar gabinetes de docentes, o edifício passou por uma reforma em 2010 para comportar também uma cantina, área de refeição, depósito e banheiros. 0 ambiente de trabalho possui uma organização do tipo celular (Duffy et al., 1976), onde um longo corredor central dá acesso aos escritórios individuais (Figura 1).

O bloco possui geometria laminar, com as fachadas principais orientadas para noroeste e sudeste. A fachada sudeste recebe um corredor avarandado, que sombreia as esquadrias no período da manhã. A fachada noroeste, por sua vez, além da projeção do beiral, possui também uma série de brises verticais que demarcam a modulação separando cada gabinete e, junto à vegetação, bloqueiam a incidência direta de sol no período da tarde, durante a maior parte do ano, como será visto adiante. As esquadrias, de ferro e vidro, podem ter sua abertura e angulação reguladas pelos ocupantes. A Figura 2 apresenta fotografias das duas maiores fachadas do edifício. 


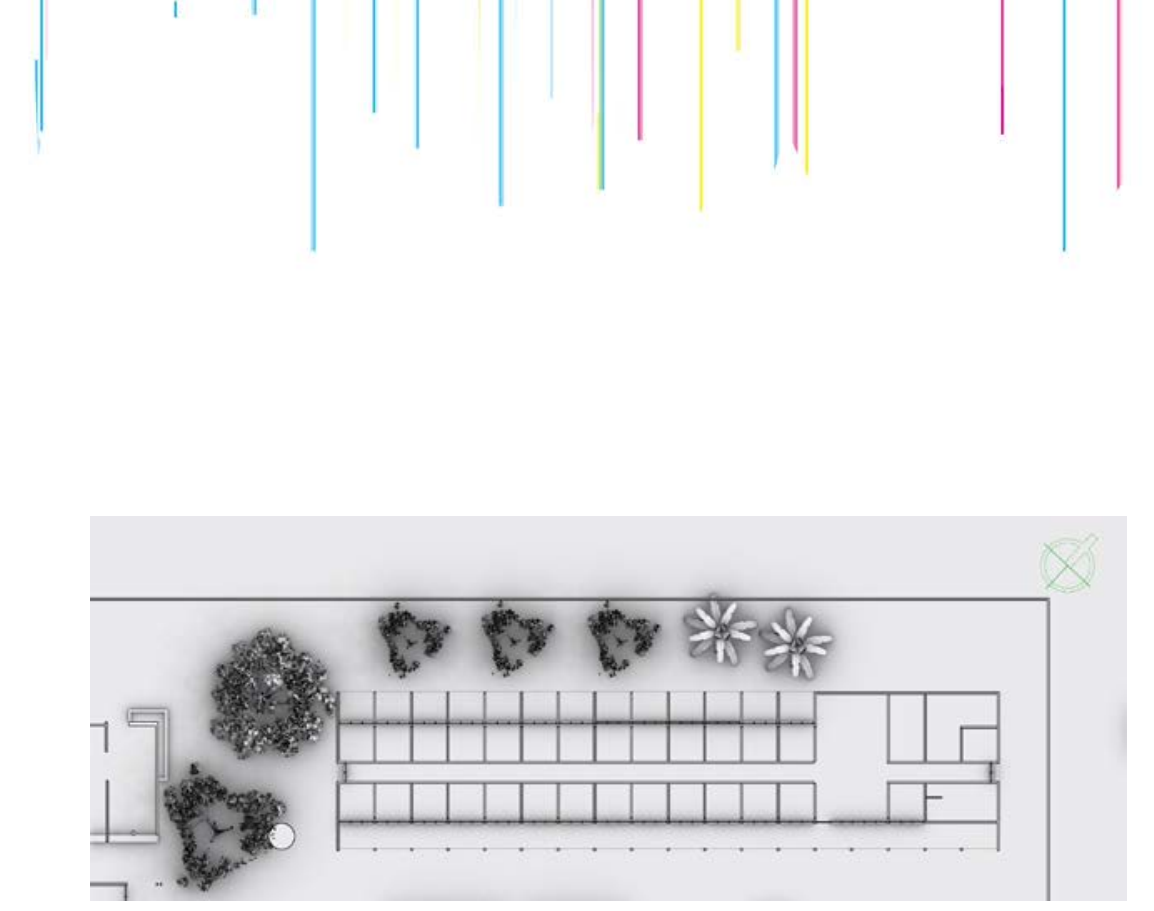

Figura 1. Planta baixa do objeto de estudo, com massas arbóreas adjacentes. Fonte: Elaborado pelos autores no software Rhinoceros 7.
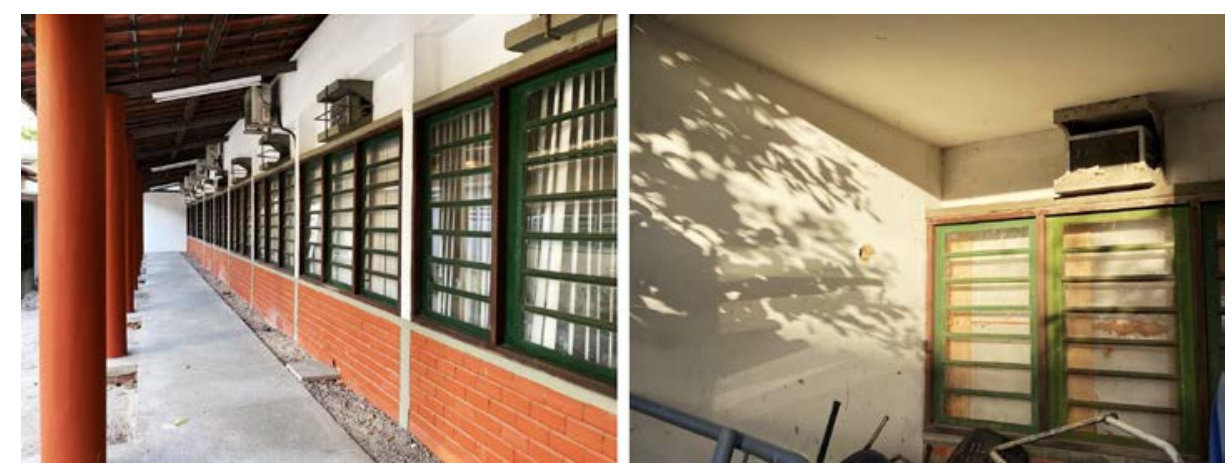

Figura 2. Corredor avarandado da fachada sudeste (esquerda) e momento de incidência do sol da tarde na fachada noroeste (direita), durante o inverno (29/07/2021, às 17h) Fonte: Acervo dos autores, 2021.

A Figura 2 também exibe algumas modificações feitas pelos ocupantes do edifício. É possível observar a colocação de ar condicionado em diversas salas, bem como a utilização de cortinas ou tábuas para reduzir a entrada de luz e conferir maior privacidade aos escritórios. Nota-se, assim, que apesar da possibilidade de operação das esquadrias para entrada de luz e fluxo de ar, os ocupantes sentiram a necessidade de aplicar estratégias ativas de condicionamento ambiental, o que repercutiu em uma configuração isolada dos gabinetes em relação ao espaço exterior. Vale mencionar, também, que algumas salas foram aglutinadas, abrigando grupos de estudos, laboratórios ou espaços de trabalho conjunto de docentes. Além disso, a área externa à fachada noroeste, recuo entre edifício e o muro, encontra-se subutilizada, não recebendo uso como espaço de permanência nem de circulação.

\section{Metodologia}

Na corrente pesquisa, analisou-se a interação dos fenômenos climáticos com o edifício estudado. Essa análise foi respaldada nas simulações 
implementadas por intermédio de instrumentos paramétricos, que permitiram considerar a influência dos elementos constituintes no entorno como arborização, edifícios adjacentes, e a orientação solar das fachadas. Após a obtenção de dados, foram realizadas simulações para a compreensão da situação atual, e a partir disso foram levantadas as principais demandas de intervenção. Dessa forma, foram feitas novas simulações para se explorar o potencial de adaptabilidade conexo a alguns elementos do objeto de estudo, considerando uma maior qualidade ambiental sob o ponto de vista da relação entre o edifício e o meio.

\subsection{Obtenção de Dados}

Tendo em vista os conceitos apresentados, elencaram-se duas principais formas de obtenção de dados do objeto de estudo: (1) por meio de simulações computacionais paramétricas e (2) por meio levantamentos de dados climáticos realizados in loco, utilizando equipamentos capazes de aferir temperaturas superficiais e quantidade de luz dentro do ambiente.

As simulações paramétricas foram realizadas utilizando o software Rhinoceros, vinculado ao Grasshopper (Robert McNeel \& Associates, 2021), partindo de uma modelagem 3D do espaço. No ambiente do Grasshopper, utilizou-se o plugin Ladybug, que torna viável fazer simulações climáticas para calcular a incidência solar em determinadas superfícies e em diferentes períodos do ano. Ademais, é possível conceber uma análise que demonstre os vetores dos raios solares e suas interações com o modelo, sendo assim capaz de entender e visualizar melhor a incidência dos raios solares e os efeitos de suas reflexões.

No tocante à visita presencial, foram utilizados os seguintes equipamentos: uma câmera termográfica modelo FLIR C2, que é capaz de fazer registros fotográficos que medem a temperatura radiante das superfícies com base num gráfico de cores, e um luxímetro Digital Minipa MLM-1020, que mede a quantidade de luz existente no ambiente.

Ao iniciar o processo de análise do objeto de estudo, primeiramente, analisaram-se as informações relativas ao macroclima no qual a construção está inserida. Com esse objetivo, foram levantados dados climáticos da cidade de Fortaleza, no estado do Ceará, Brasil. A cidade possui temperatura de bulbo seco estável ao longo de todo o ano, variando entre $20^{\circ} \mathrm{C}$ e $35^{\circ} \mathrm{C}$, além disso destaca-se uma dualidade entre estação chuvosa e período de estiagem, sempre com umidade relativa do ar considerável (acima de 65\%), por ser uma cidade litorânea. Há, também, elevado índice de incidência de radiação solar.

As informações utilizadas foram obtidas a partir de um arquivo EPW (Energy Plus Weatherfile), composto no formato TMY (Typical Meteorologycal Year), que se resume a um ano climático sem extremos, obtido a partir da combinação de meses típicos provenientes de vários anos.

Partindo para a escala do entorno do objeto de estudo, foram consideradas suas características qualitativas para caracterização de cenários possíveis. Já nas simulações paramétricas, foi feita uma simplificação, adotando-se apenas o modelo do edifício, com sua geometria básica e aberturas. 


\subsection{Simulações de Radiação}

Em uma perspectiva analítica distinta, algumas simulações de radiação incidente foram implementadas com o intuito de quantificar o índice de radiação solar que atinge os planos de cobertura do objeto de estudo. Em consonância com as terminologias de Roudsari e Pak:

Radiation is an important factor to consider in occupant thermal comfort and energy use of the buildings. Although the amount of radiation received by a surface has a direct relationship with the orientation (horizontal angle) and vertical angle of the surface, most of the visualization methods do not address this relationship. The radiation data is usually visualized as tabular 2D graphs, averaged weekly or monthly, or 3D graphs which only show the amount of the radiation for a specific period of time. (Roudsari \& Pak, 2013, p. 8)

Consequentemente, torna-se manifesto que essa classe de análise paramétrica é impreterível para a conformação de compreensões amplas e resolutas concernentes ao condicionamento ambiental, uma vez que esclarece particularidades elementares acerca do conforto térmico, e do desempenho energético do edifício. A simulação implementada no componente Ladybug (Ladybug Tools LCC, 2021) possibilita ao projetista visualizar com mais clareza a correlação entre a orientação do edifício e a radiação solar incidente.

Como resultado dessa análise (Figura 4), observou-se que a cobertura do edifício recebe elevados índices de radiação solar direta, e não há elementos no entorno que geram sombreamento considerável na coberta. A análise foi feita considerando os intervalos mensais de março, junho, setembro e dezembro, englobando diversos períodos do ano. No mês de setembro, evidencia-se que os índices de radiação são superiores. À vista dessas informações, a coberta se expressou como elemento responsável por transmitir uma carga térmica considerável à edificação ao longo do ano. Além disso, destacam-se os brises verticais, com medidas de 2,20 m, e os longos beirais que protegem as fachadas do edifício. 

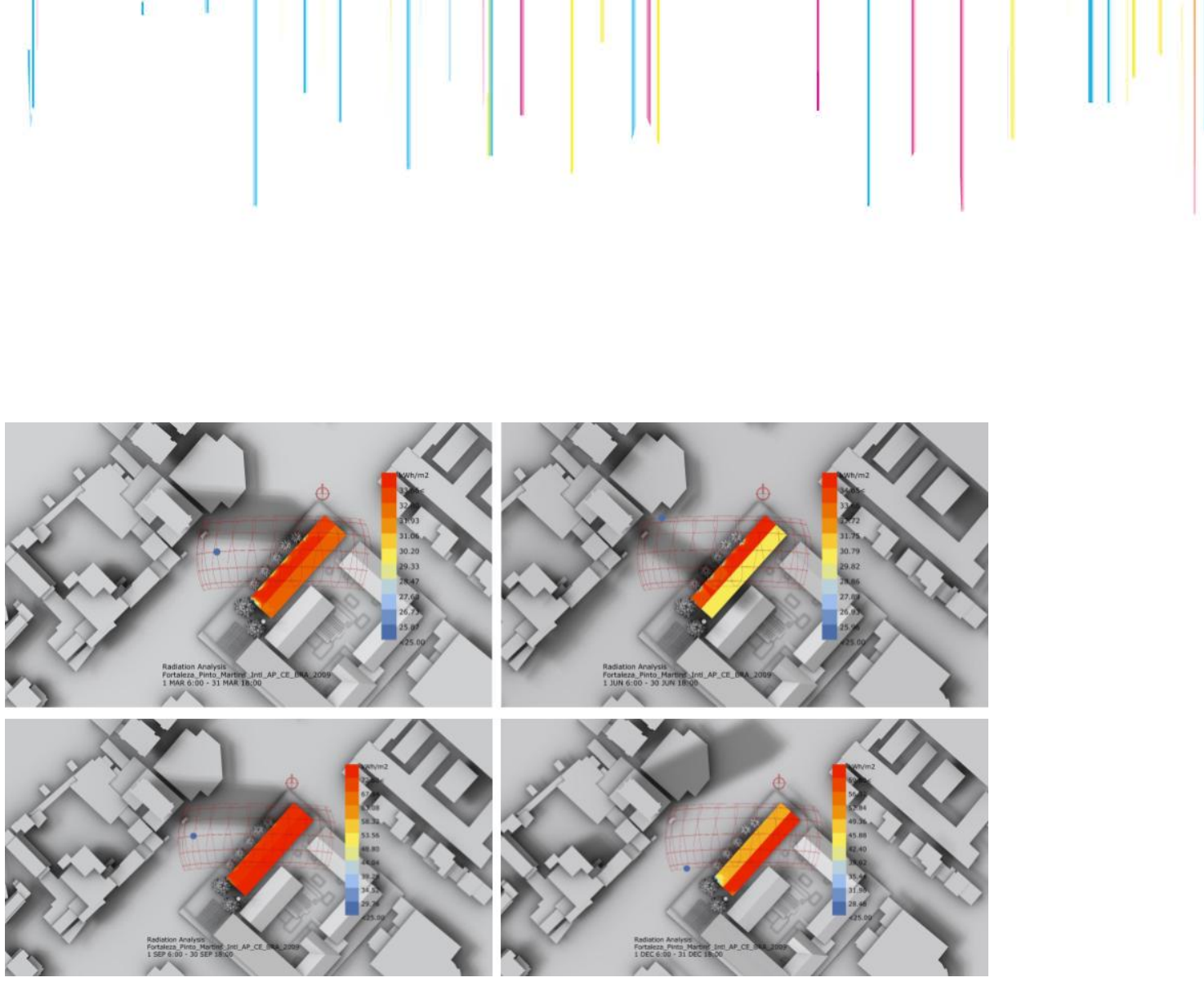

Figura 4. Resultados da simulação de radiação incidente. Fonte: Elaborado pelos autores no Rhinoceros 7+Grasshopper, com uso do Ladybug e dados do INMET (2018).

Outra estratégia complementar implementada para compreender a relação entre a radiação solar incidente e as temperaturas foi o registro de imagens termográficas. Na imagem termográfica, as cores quentes representam as temperaturas superficiais maiores, e as cores frias, as temperaturas superficiais menores, como ilustra a Figura 5. Tornou-se possível observar que em virtude das proteções dos brises, a radiação que atinge o plano de fachada não é considerável.

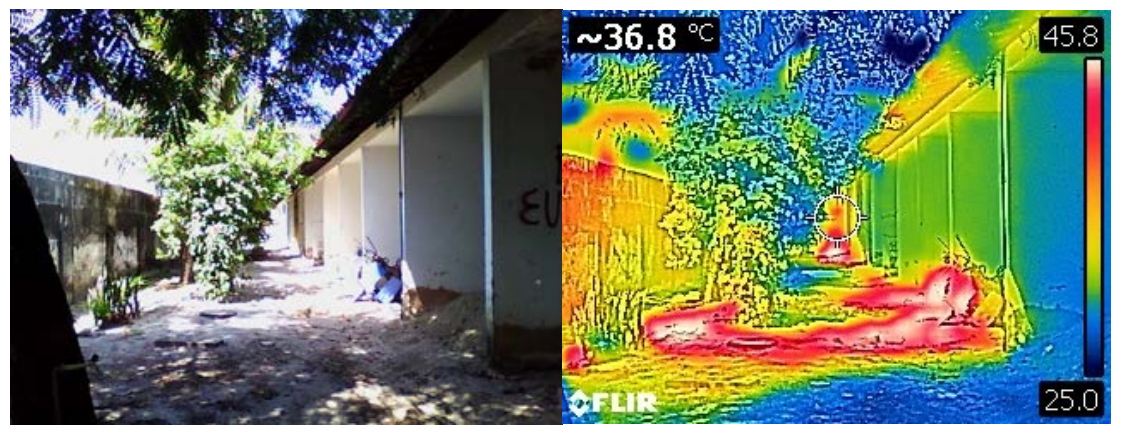

Figura 5. Imagem fotográfica e termográfica da fachada noroeste. Fonte: Acervo dos autores, 2021.

\subsection{Simulação de lluminação}

A fim de aprofundar o desenvolvimento do estudo, também foram feitas simulações de iluminação natural nos ambientes internos. Para analisar as particularidades da iluminação natural no edifício, elegeu-se uma sala da 
edificação, a oitava sala, que abriga um gabinete dos professores, com esquadrias voltadas para noroeste, e em uma ocular funcional, resguarda atividades como leitura e reuniões. A simulação evidencia, por meio de um gráfico de cor, uma quantificação de luz em uma malha de pontos inserida na sala, e para possibilitar uma melhor compreensão, as datas e horários utilizados na simulação se equipararam às circunstâncias nas quais o levantamento in loco foi desenvolvido (às $15 \mathrm{~h}$ do dia 8 de fevereiro). Na Figura 6, ilustra-se a simulação de luminância que demonstra a espacialização da malha de pontos no ambiente selecionado, e a categorização dos intervalos da unidade de medida lux. $\mathrm{Na}$ imagem estão ilustradas três situações diferentes, (1) com os brises originais, (2) com os brises reduzidos e (3) sem brises. A imagem também ilustra como o ambiente estudado é prejudicado pela ausência de iluminação natural em algumas regiões. No levantamento in loco, realizado na altura do plano de trabalho, a aferição média próxima à janela aproximou-se de 120 lux. A unidade lux está vinculada ao fluxo luminoso, emitido por uma fonte de luz, que incide sobre uma superfície.



Figura 6. Imagem da simulação de luminância em três situações nas quais os brises verticais possuem dimensões distintas. Fonte: Elaborado pelos autores no Rhinoceros 7+Grasshopper, com uso do Ladybug e dados do INMET (2018).

Isto posto, as atividades implementadas neste âmbito encontram alguns entraves, visto que o índice lux mínimo sugerido para essas atividades equivale a 300 lux. Além disso, a figura demonstra a relação entre a parametrização da extensão dos brises e a iluminação interna. Já a Figura 7 mostra, através de um diagrama estereográfico, como seria a insolação na fachada da sala em um contexto conjectural, no qual a extensão dos brises foi reduzida em 1,00m, ficando com 1,20m. 


\section{Discussão}

Em busca das melhores soluções para o espaço, foram testados alguns cenários, incorporando a mutabilidade de análise permitida pelo uso das ferramentas paramétricas. Notou-se que a solução de rebatimento de luz seria ineficiente, pois funcionaria apenas em alguns horários específicos do dia e durante os meses de maio, junho e julho - nos demais meses, os raios solares não poderiam ser refletidos, uma vez que seriam bloqueados pelos brises do edifício.

É fundamental destacar que o edifício existente transparece atenção aos princípios bioclimáticos como premissa de projeto, materializados no sombreamento das fachadas pelo beiral e pelos brises, na escolha dos materiais e na utilização de esquadrias que permitem controle da ventilação como comenta Gonçalves (2019) a respeito do legado da arquitetura moderna brasileira. Contudo, o dimensionamento desses elementos focado no máximo de sombreamento e as modificações na ocupação do edifício levaram a uma redução da qualidade ambiental ao longo do tempo. Características como a possibilidade de operação das esquadrias e a modificação dos layouts internos podem contribuir para futuras intervenções, considerando a adaptabilidade. Além disso, o planejamento do espaço de maneira mais holística, considerando uma relação porosa entre o edifício e o ambiente externo e destinando-se mais atenção à materialidade e à presença de áreas verdes no entorno, é essencial para que esses gabinetes sejam mais bem aproveitados.

Em virtude das condições sanitárias relacionadas à pandemia de Covid 19, o edifício estava desocupado, portanto não foi possível abranger neste estudo uma avaliação de pós-ocupação. Em trabalhos futuros, a inclusão dessa etapa possibilitará incorporar a percepção dos ocupantes a respeito do conforto térmico. Além disso, análises de ventilação natural, estratégia bioclimática fundamental para o clima local, devem ser consideradas.

O uso de ferramentas paramétricas demonstrou ser uma importante ferramenta de análise da performance ambiental, que permite implantar diversos parâmetros e gerar simulações dos mais diferentes aspectos. Esse processo possibilitou avaliar distintas soluções relacionadas ao desempenho de conforto térmico-lumínico. A implementação das simulações paramétricas foi essencial em duas perspectivas: à primeira vista elas possibilitaram uma particularizada compreensão dos fenômenos e variáveis climáticas que interagem com o objeto de estudo, e simultaneamente, concederam possibilidades de reconfiguração, com soluções que resguardam um desempenho potencializado.

Agradecimentos. Agradecemos ao Departamento de Arquitetura e Urbanismo e Design da Universidade Federal do Ceará pela cessão dos equipamentos utilizados para medição in loco. 


\section{Referências}

Duffy, F., Cave, C., \& Worthington, J. (Eds.). (1976). Planning Office Space. Architectural Press.

Frota, A. B., \& Schiffer, S. R. (2001). Manual de conforto térmico (5a). Studio Nobel.

Gonçalves, J. C. S. (2019). O novo ambiente de trabalho: Diversidade ambiental e flexibilidade do espaço. Revista Pós FAUUSP, 26(49), e161676-e161676. https://doi.org/10.11606/issn.2317-2762.posfau.2019.161676

Instituto Nacional de Meteorologia (INMET). (2018). Arquivos climáticos INMET 2018. Retrieved February 20 2021, from https://labeee.ufsc.br/downloads/arquivosclimaticos/inmet2018

Ladybug Tools LLC. (2021). Ladybug Tools. Computer software]. https://www.ladybug.tools/

Monteiro, L. M., Bittencourt, L., \& Yannas, S. (2015). Arquitetura da adaptação. In J. C. S. Gonçalves \& K. Bode (Eds.), Edifício ambiental (pp. 27-55). Oficina de Textos.

Oxman, R. (2006). Theory and design in the first digital age. Design Studies, 27(3), 229265. https://doi.org/10.1016/j.destud.2005.11.002

Robert McNeel \& Associates. (2021). Rhinoceros 7. Computer software]. https://www.rhino3d.com/

Roudsari, M., \& Pak, M. (2013). Ladybug: A parametric environmental plugin for Grasshopper to help designers create an environmentally-conscious design. In: Proceedings of BS2013 (pp. 3128-3135). Chambéry, France.

Tsuda, F. P., \& Duarte, D. H. S. (2018). Reabilitação de edifícios residenciais: Estudos de adequação ambiental. Arquitextos (Vitruvius), 218.01. https://vitruvius.com.br/revistas/read/arquitextos/19.218/7024 